\title{
Specific heat of a gas is same in both isochoric and isobaric process
}

\author{
Sankar Palchoudhury ${ }^{1,2}$ \\ ${ }^{1}$ 101/673/A, College Para, P.O. Kharia, Ward No. 21, Dist. Jalpaiguri, Pin Code -735101, West Bengal, India \\ ${ }^{2} \mathrm{CMOH}$ Office, Jalpaiguri, Government of West Bengal, India \\ E-mail addresses: sankarpalchoudhury@gmail.com,_cmoh_jal@wbhealth.gov.in
}

Received March 2018

Received in revised: March 2018

Published: June 2018

\begin{abstract}
The Palchoudhury gas theory and Palchoudhury gas equation have a profound potency applicable to all phenomena of gases. Inner and covered outer surface area of molecules are the outstanding inventions related to gas behaviour. The exertion of infrared wave force on the covered outer surface area of tiny particles and the corresponding effect on the inner surface of a gas container is the real cause of the gas behaviour. We can independently explain all kind of behaviour of gases with the help of the conception the inner force and internal force. We can clarify about the isothermal and adiabatic behaviour of gases, show the relation between heat and force. It is most significant finding, the specific heat of an identical gas in the isochoric and the isobaric process is not different but same as the inner force in both methods is same.
\end{abstract}

Keywords: Specific Heat, Isothermal, Adiabatic

C2018 The Authors. Published by Fundamental Journals. This is an open access article under the CC BY-NC https://creativecommons.org/licenses/by-nc/4.0/

https://doi.org/10.14331/ijfps.2018.330116

\section{INTRODUCTION}

Heat, i.e. infrared wave call it as the heat wave. Heat wave holds some force during play up and down in the universe like an ocean wave. Heat wave exerts some force on the outer surface of tiny particles like atoms, molecules, etc. And in turn, the corresponding force consecutively and cumulatively uses an effect on the inner surface of a closed gas container. Every heat wave holds some energy that transfers to the gases and gases become hot. Again, some external force applies to gas that forces transfers into the heat of gases. It is comprehensive text, and the gases have no specific shape and size. According to Palchoudhury gas theory Palchoudhury (2016), the gas behaviour depends only on four variable (Pressure, temperature, inner surface area and outer surface area). Four variables compatible with Van der Waals constant and fit in all process-like the isochoric, isobaric, isothermal and adiabatic process of gases. 


\section{ANALYSIS OF ISOCHORIC AND ISOBARIC PROCESS}

On in-depth analysis of the isochoric and isobaric processes of gases shown in the Table 1 and Table 2, reveals the following information,

a) The inner force of the identical gases is the same in both isochoric and isobaric process on increment $1^{\mathrm{oK}}$ temperature.

b) The inner force of gases in the isochoric and isobaric process is different for different gases. It is remarkable, the inner force in the isochoric and isobaric process is different for the different size (inner surface area) of same gas as shown for carbon dioxide in Table1 and 2.

c) For increment $1^{\mathrm{oK}}$ temperature of gases, the internal force of the isochoric process is comparatively higher than isobaric process shown in Table 1 and Table 2. The excess internal force as seen in the isochoric process, the same spends for expanding the inner surface area in the isobaric process and the force remains as a static force (see the Table 2).

d) Per unit internal force which depends on the covered outer surface of a substance and the inner surface area is a field intensity of gases.

e) The equal heat wave force requires during the increment of $1^{\mathrm{oK}}$ temperature of gases as found inner force is the same in both for the isochoric and isobaric processes shown in Table 1 and Table 2.

\section{REGARDING HEAT CAPACITY OF GASES}

There is an excellent role of size (inner surface area) of a gas in the effect of inner and internal force on increasing $1^{\text {oK }}$ temperature of gases. In Table 1 and Table 2 reveals, the inner force effects heavily on the smallest inner surface area than the larger inner surface area as seen for one-mole carbon dioxide gas. Much more heat wave force requires for the smallest inner surface area than the larger inner surface area to rise $1^{\mathrm{oK}}$ temperature of gases. According to the Palchoudhury gas equation $P S=C n A T$ where $P$ here is pressure, $S$ Inner surface area, $C$ is constant of proportionality, $n$ is number of moles, $A$ covered outer surface area of molecules and $T$ is temperature, Palchoudhury (2016) $P S=F$, that $F$ is the inner force (Palchoudhury, 2017a, 2017b), corresponding to heat depends on the product of pressure and inner surface area. Again, $P S \propto$ $A \mathrm{~T}$, the inner force corresponding to heat depends on the outcome of the covered outer surface area of tiny particles and temperature.

There is a significant role of the substance per unit inner surface area in the effect of gas behaviour as the internal force depends on the covered outer surface area of the substance. The ratio of internal force which depends on the elements, and the inner surface area have a significant role in the behaviour of gases.

The specific heat of gases is a comparative matter. We may use any gas as a mediator. General text in the standard textbook, $1 \mathrm{cal}=4.18 \mathrm{~J}$ and $C v_{m}$ (Isochoric) $=\mathrm{H}=4.82$ $\mathrm{cal} / \mathrm{mole}{ }^{O} \mathrm{~K}$ for Carbon monoxide, and we may treat it as corresponding $C s_{m}$ (Isochoric) $=\mathrm{H}=4.82 \mathrm{cal} / \mathrm{mole}-\mathrm{K}$ (Heat capacity under constant inner surface area of one mole carbon monoxide). Therefore, $\mathrm{H}=4.82$ /cal for one mole Carbon monoxide. Now,

$$
F \propto H \quad \text { or } \quad F=V H
$$

so that $F$ is inner force, $H$ is heat and $V$ is nominated as the constant of proportionality. On conceptual based argument, we may accept carbon monoxide (CO) as a mediator. Now, for one mole Carbon monoxide at temperature, 274 ${ }^{\mathrm{ok}}$ and with inner surface area of $1.65 \mathrm{dm}^{2}$ (square decimeter), covered outer surface area of $0.009 \mathrm{dm}^{2}$, and pressure $10.45 \mathrm{MPa}$ (Mega Pascal), when for increasing $1^{o K}$ (from $273^{\circ \mathrm{K}}$ to $274^{\mathrm{oK}}$ ) in temperature, increase of the inner force $F=630.77 \mathrm{~N}$ mole $\mathrm{K}$ (column-13/100) in Table 1 and when $C s_{m}=H=4.82$ $\mathrm{cal} / \mathrm{mole}-\mathrm{K}$ then, $V=130.73 \mathrm{~N} / \mathrm{cal}$ (about). In this paper we have used the following phrases in all Tables, as below;

1- The common gases are as, $\mathrm{Co}_{2}, \mathrm{He}, \mathrm{Ne}, \mathrm{H}, \mathrm{Ar}, \mathrm{O}, \mathrm{N}, \mathrm{Co}$, $\mathrm{CH}_{4}$ and $\mathrm{NH}_{3}$.

2- The volume for the gases, $\mathrm{He}, \mathrm{Ne}, \mathrm{H}, \mathrm{Ar}, \mathrm{O}, \mathrm{N}, \mathrm{Co}, \mathrm{CH}_{4}$ and $\mathrm{NH}_{3}$ is 0.2 and for $\mathrm{Co}_{2}$, is $0.05,0.2$ and 22.4 in SI unit.

3- We have selected one mole $(n=1)$ for all gases.

4- The constant value is $C=6.681$.

5- The inner surface $(S)$ for the common gases, $\mathrm{He}, \mathrm{Ne}, \mathrm{H}, \mathrm{Ar}$, $\mathrm{O}, \mathrm{N}, \mathrm{Co}, \mathrm{CH}_{4}$ and $\mathrm{NH}_{3}$ is 1.65 and for $\mathrm{Co}_{2}$ is $0.66,1.65$ and 38.43 .

6- The temperature $T$ is $273^{\mathrm{oK}}$, and the inner force of the identical gases is the same in both isochoric and isobaric process on increment $1^{\mathrm{oK}}$.

7- Here $F_{b e}$ and $F_{a f}$ are the forces on whole inner surface area before and after increment $1^{\mathrm{oK}}$, respectively in SI unit $\left(\mathrm{N} / \mathrm{m}^{2}\right)$.

and

$$
F_{b e}=\left(S P_{b e}\right) \times 10^{-6}
$$

$$
F_{a f}=\left(S P_{a f}\right) \times 10^{-6}
$$

where $P_{b e}$ and $P_{b e}$ are the pressure before and after temperature increment with $1^{\mathrm{oK}}$ and in SI unit respectively.

8- The difference between the forces, defined by $\Delta F=F_{b e}-$ $F_{a f}$ and is in the SI unit $\left(\mathrm{N} / \mathrm{m}^{2}\right)$.

9- The $F_{\text {int }}$ is defined as the internal force on the outer surface $A$ covered outer surface area of molecules of gases by heat wave force and following the below,

$$
F_{\text {int }}=\left(A P_{a f}\right) \times 10^{6}
$$

10- Here $C_{p}$ is the specific heat capacity of gases in Kcal and then the Heat of gases is the heat of gases after increment of 1 $\mathrm{k}$ temperature of gases bears total heat in $\mathrm{kcal}$. This value will be producing by,

$$
\mathrm{H}_{\text {gas }}=\frac{F_{a f}}{130.7398 \times 10^{3}}
$$

11- Moreover the heat on outer surface is the heat of outer the surface after increment $1 \mathrm{~K}$ temperature, outer surface of molecules bear total heat in Kcal and is

$$
\mathrm{H}_{\text {out }}=\frac{A P_{a f}}{130.7398 \times 10^{3}}
$$

and mentioned as $\mathrm{H}_{\text {out }}$ in the table. 
Table 1. The relation between force and heat in isochoric process for individual gases and heat capacity of gases.

\begin{tabular}{c|c|c|c|c|c|c|c|c|c|c|c|c}
\hline $\begin{array}{c}\text { Common } \\
\text { Gases }\end{array}$ & $\mathrm{V}$ & $\mathrm{A}$ & $\mathrm{S}$ & $P_{\text {be }}$ & $P_{a f}$ & $F_{\text {be }}$ & $F_{a f}$ & $\Delta F$ & $F_{\text {int }}$ & $\mathrm{Cp}$ & $\mathrm{H}_{\text {gas }}$ & $\mathrm{H}_{\text {out }}$ \\
\hline & 0.05 & 0.059 & 0.66 & 164.09 & 164.69 & 107700436.37 & 108094943.46 & 394507.09 & 9725392.50 & 3.02 & 826.79 & 74.370 \\
$\mathbf{C O 2}$ & 0.2 & 0.005 & 1.65 & 5.33 & 5.35 & 8813175.41 & 8845458.11 & 32282.69 & 25844.24 & 0.25 & 67.66 & 0.198 \\
& 22.4 & 0.002 & 38.43 & 0.10 & 0.10 & 3873704.03 & 3887893.42 & 14189.39 & 214.89 & 0.11 & 29.74 & 0.002 \\
\hline $\mathbf{H e}$ & 0.2 & 0.012 & 1.65 & 12.79 & 12.84 & 21151318.25 & 21228795.60 & 77477.36 & 148858.54 & 0.59 & 162.37 & 1.138 \\
$\mathbf{N e}$ & 0.2 & 0.011 & 1.65 & 11.88 & 11.92 & 19642006.82 & 19713955.57 & 71948.74 & 128372.09 & 0.55 & 150.79 & 0.982 \\
$\mathbf{H}$ & 0.2 & 0.011 & 1.65 & 12.47 & 12.52 & 20627734.13 & 20703293.60 & 75559.47 & 141580.01 & 0.58 & 158.35 & 1.083 \\
$\mathbf{A r}$ & 0.2 & 0.009 & 1.65 & 10.12 & 10.16 & 16736743.54 & 16798050.30 & 61306.75 & 93205.34 & 0.47 & 128.48 & 0.713 \\
$\mathbf{O}$ & 0.2 & 0.010 & 1.65 & 10.57 & 10.61 & 17480533.09 & 17544564.35 & 64031.26 & 101673.61 & 0.49 & 134.19 & 0.778 \\
$\mathbf{N}$ & 0.2 & 0.010 & 1.65 & 10.59 & 10.63 & 17513337.08 & 17577488.50 & 64151.42 & 102055.57 & 0.49 & 134.45 & 0.780 \\
$\mathbf{C O}$ & 0.2 & 0.009 & 1.65 & 10.41 & 10.45 & 17220252.77 & 17283330.62 & 63077.85 & 98668.36 & 0.48 & 132.20 & 0.755 \\
$\mathbf{C H 4}$ & 0.2 & 0.008 & 1.65 & 8.73 & 8.76 & 14439592.78 & 14492485.06 & 52892.28 & 69375.92 & 0.40 & 110.85 & 0.531 \\
$\mathbf{N H 3}$ & 0.2 & 0.003 & 1.65 & 3.37 & 3.38 & 5571507.79 & 5591916.25 & 20408.45 & 10328.67 & 0.16 & 42.77 & 0.079 \\
\hline
\end{tabular}

Data (column 1 to 14) collected from (Palchoudhury, 2017a), $1 \mathrm{MPa}=10^{6} \mathrm{~N} / \mathrm{m}^{2}, 1 \mathrm{kcal}=1000 \mathrm{cal}, \mathrm{N}=$ Newton (Force)

Table 2. The relation between force and heat in isobaric process for individual gases and heat capacity of gases.

\begin{tabular}{|c|c|c|c|c|c|c|c|c|c|c|c|c|c|c|}
\hline $\begin{array}{c}\text { Common } \\
\text { Gases }\end{array}$ & V & A & $S_{b e}$ & $\mathrm{P}$ & $S_{a f}$ & $F_{b e}$ & $F_{a f}$ & $\Delta F$ & $F_{\text {int }}$ & $\mathrm{Cp}$ & $\mathrm{H}_{\text {gas }}$ & $\mathrm{H}_{\text {out }}$ & $\Delta S$ & $\begin{array}{c}F_{\text {int }} \\
\text { (spent) }\end{array}$ \\
\hline \multirow{3}{*}{$\mathrm{CO}_{2}$} & 0.05 & 0.059 & 0.656 & 164.09 & 0.659 & 107700436.37 & 108094943.46 & 394507.09 & 9689898.37 & 3.017 & 826.79 & 74.099 & 0.002 & 35494.13 \\
\hline & 0.2 & 0.005 & 1.654 & 5.33 & 1.660 & 8813175.41 & 8845458.11 & 32282.69 & 25749.91 & 0.247 & 67.66 & 0.197 & 0.006 & 94.32 \\
\hline & 22.4 & 0.002 & 38.428 & 0.10 & 38.569 & 3873704.03 & 3887893.42 & 14189.39 & 214.10 & 0.109 & 29.74 & 0.002 & 0.141 & 0.78 \\
\hline He & 0.2 & 0.012 & 1.654 & 12.79 & 1.660 & 21151318.25 & 21228795.60 & 77477.36 & 148315.26 & 0.593 & 162.37 & 1.134 & 0.006 & 543.28 \\
\hline $\mathrm{Ne}$ & 0.2 & 0.011 & 1.654 & 11.88 & 1.660 & 19642006.82 & 19713955.57 & 71948.74 & 127903.58 & 0.550 & 150.79 & 0.978 & 0.006 & 468.51 \\
\hline $\mathbf{H}$ & 0.2 & 0.011 & 1.654 & 12.47 & 1.660 & 20627734.13 & 20703293.60 & 75559.47 & 141063.29 & 0.578 & 158.35 & 1.079 & 0.006 & 516.72 \\
\hline Ar & 0.2 & 0.009 & 1.654 & 10.12 & 1.660 & 16736743.54 & 16798050.30 & 61306.75 & 92865.18 & 0.469 & 128.48 & 0.710 & 0.006 & 340.17 \\
\hline $\mathbf{O}$ & 0.2 & 0.010 & 1.654 & 10.57 & 1.660 & 17480533.09 & 17544564.35 & 64031.26 & 101302.54 & 0.490 & 134.19 & 0.775 & 0.006 & 371.07 \\
\hline $\mathbf{N}$ & 0.2 & 0.010 & 1.654 & 10.59 & 1.660 & 17513337.08 & 17577488.50 & 64151.42 & 101683.10 & 0.491 & 134.45 & 0.778 & 0.006 & 372.47 \\
\hline $\mathrm{CO}$ & 0.2 & 0.009 & 1.654 & 10.41 & 1.660 & 17220252.77 & 17283330.62 & 63077.85 & 98308.26 & 0.482 & 132.20 & 0.752 & 0.006 & 360.10 \\
\hline CH4 & 0.2 & 0.008 & 1.654 & 8.73 & 1.660 & 14439592.78 & 14492485.06 & 52892.28 & 69122.73 & 0.405 & 110.85 & 0.529 & 0.006 & 253.20 \\
\hline NH3 & 0.2 & 0.003 & 1.654 & 3.37 & 1.660 & 5571507.79 & 5591916.25 & 20408.45 & 10290.97 & 0.156 & 42.77 & 0.079 & 0.006 & 37.70 \\
\hline
\end{tabular}

$S_{b e}$ and $S_{a f}$ are the inner surface area before and after temperature increment with $1^{\text {oK }} . F_{\text {int }}$ (spent $)=F_{\text {int }}$ of Table 1 minus $\boldsymbol{F}_{\text {int }}$ of Table 2.

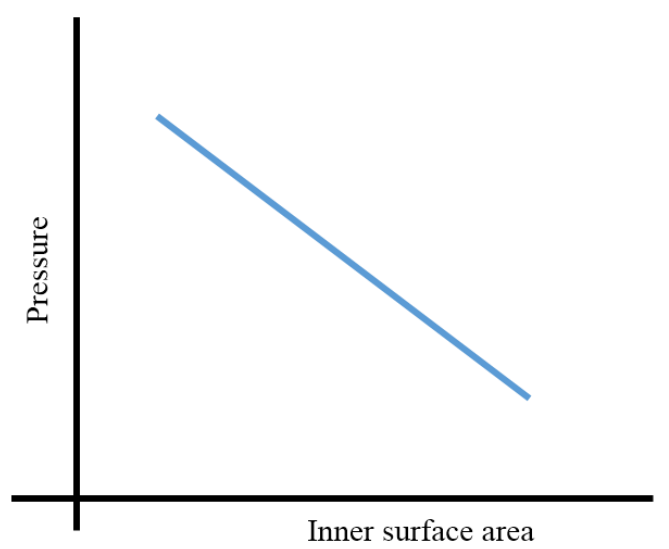

Fig 1. Isothermal Process. (Unchanged temperature Outer surface area ) 
Table 3. Behaviour of gases under compression and expansion in isothermal process.

\begin{tabular}{|c|c|c|c|c|c|c|c|c|c|c|c|}
\hline \multirow{2}{*}{$\begin{array}{l}\text { Common } \\
\text { Gases }\end{array}$} & \multirow[t]{2}{*}{ V } & \multirow{2}{*}{$A_{b e}$} & \multirow{2}{*}{$S_{b e}$} & \multirow{2}{*}{$P_{b e}$} & \multirow{2}{*}{$A_{a f}$} & \multirow{2}{*}{$S_{a f}$} & \multirow{2}{*}{$P_{a f}$} & \multirow{2}{*}{$F_{b e}$} & \multirow{2}{*}{$F_{a f}$} & \multicolumn{2}{|c|}{$\begin{array}{l}\text { Gases gains after } \\
\text { isothermal expansion }\end{array}$} \\
\hline & & & & & & & & & & $F_{\text {gain }}$ & $\mathrm{H}_{\text {gain }}$ \\
\hline \multirow{3}{*}{$\mathrm{CO}_{2}$} & 0.05 & 0.059 & 0.656 & 164.09 & 0.060 & 0.69 & 159.40 & 107700436.37 & 109854445.1 & 2154009 & 16.47554 \\
\hline & 0.2 & 0.005 & 1.654 & 5.33 & 0.005 & 1.74 & 5.18 & 8813175.41 & 8989438.92 & 176263.5 & 1.348201 \\
\hline & 22.4 & 0.002 & 38.428 & 0.10 & 0.002 & 40.35 & 0.10 & 3873704.03 & 3951178.11 & 77474.08 & 0.592582 \\
\hline He & 0.2 & 0.012 & 1.654 & 12.79 & 0.012 & 1.74 & 12.42 & 21151318.25 & 21574344.61 & 423026.4 & 3.235636 \\
\hline $\mathbf{H}$ & 0.2 & 0.011 & 1.654 & 12.47 & 0.012 & 1.74 & 12.12 & 20627734.13 & 21040288.81 & 412554.7 & 3.15554 \\
\hline $\mathbf{A r}$ & 0.2 & 0.009 & 1.654 & 10.12 & 0.009 & 1.74 & 9.83 & 16736743.54 & 17071478.41 & 334734.9 & 2.560313 \\
\hline $\mathbf{O}$ & 0.2 & 0.010 & 1.654 & 10.57 & 0.010 & 1.74 & 10.27 & 17480533.09 & 17830143.75 & 349610.7 & 2.674095 \\
\hline $\mathbf{N}$ & 0.2 & 0.010 & 1.654 & 10.59 & 0.010 & 1.74 & 10.29 & 17513337.08 & 17863603.82 & 350266.7 & 2.679113 \\
\hline $\mathrm{CO}$ & 0.2 & 0.009 & 1.654 & 10.41 & 0.010 & 1.74 & 10.11 & 17220252.77 & 17564657.82 & 344405.1 & 2.634279 \\
\hline CH4 & 0.2 & 0.008 & 1.654 & 8.73 & 0.008 & 1.74 & 8.48 & 14439592.78 & 14728384.64 & 288791.9 & 2.208905 \\
\hline NH3 & 0.2 & 0.003 & 1.654 & 3.37 & 0.003 & 1.74 & 3.27 & 5571507.79 & 5682937.95 & 111430.2 & 0.852305 \\
\hline
\end{tabular}

Here $F_{\text {gain }}$ is the difference between $F_{a f}$ and $F_{b e}$ and $\mathrm{H}_{\text {gain }}$ is the convert into heat of $F_{\text {gain }}$

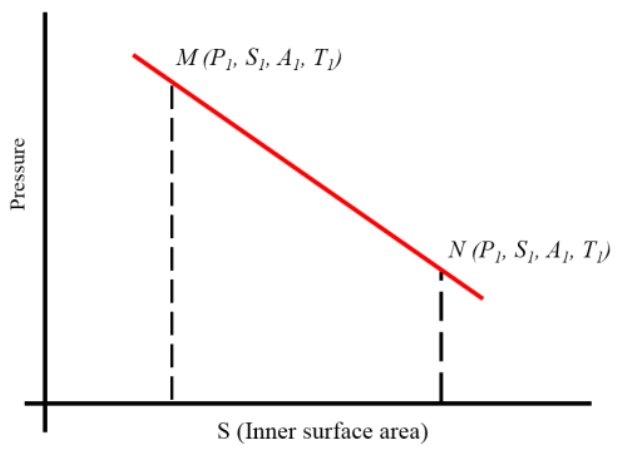

Fig 2. Adiabatic Process

Table 4. Behaviour of gases under compression and expansion in adiabatic process

\begin{tabular}{|c|c|c|c|c|c|c|c|c|c|c|c|}
\hline \multirow{2}{*}{$\begin{array}{l}\text { Common } \\
\text { Gases }\end{array}$} & \multirow[t]{2}{*}{ V } & \multirow[t]{2}{*}{$A_{b e}$} & \multirow[t]{2}{*}{$S_{b e}$} & \multirow[t]{2}{*}{$P_{b e}$} & \multirow[t]{2}{*}{$A_{a f}$} & \multirow[t]{2}{*}{$S_{a f}$} & \multirow[t]{2}{*}{$P_{a f}$} & \multirow[t]{2}{*}{$F_{b e}$} & \multirow[t]{2}{*}{$F_{a f}$} & \multicolumn{2}{|c|}{$\begin{array}{c}\text { Gases discharges after } \\
\text { adiabatic expansion }\end{array}$} \\
\hline & & & & & & & & & & $F_{\text {disc }}$ & $\mathrm{H}_{\text {disc }}$ \\
\hline \multirow{3}{*}{$\mathrm{CO}_{2}$} & 0.05 & 0.059 & 0.656 & 164.09 & 0.056 & 0.69 & 142.69 & 107700436.37 & 98335181.00 & 9365255.36 & 71.63 \\
\hline & 0.2 & 0.005 & 1.654 & 5.33 & 0.005 & 1.74 & 4.63 & 8813175.41 & 8046812.33 & 766363.08 & 5.86 \\
\hline & 22.4 & 0.002 & 38.428 & 0.10 & 0.002 & 40.35 & 0.09 & 3873704.03 & 3536860.20 & 336843.83 & 2.58 \\
\hline He & 0.2 & 0.012 & 1.654 & 12.79 & 0.011 & 1.74 & 11.12 & 21151318.25 & 19312073.18 & 1839245.06 & 14.07 \\
\hline $\mathrm{Ne}$ & 0.2 & 0.011 & 1.654 & 11.88 & 0.010 & 1.74 & 10.33 & 19642006.82 & 17934006.23 & 1708000.59 & 13.06 \\
\hline $\mathbf{A r}$ & 0.2 & 0.009 & 1.654 & 10.12 & 0.009 & 1.74 & 8.80 & 16736743.54 & 15281374.54 & 1455369.00 & 11.13 \\
\hline $\mathbf{O}$ & 0.2 & 0.010 & 1.654 & 10.57 & 0.009 & 1.74 & 9.19 & 17480533.09 & 15960486.74 & 1520046.35 & 11.63 \\
\hline $\mathbf{N}$ & 0.2 & 0.010 & 1.654 & 10.59 & 0.009 & 1.74 & 9.21 & 17513337.08 & 15990438.21 & 1522898.87 & 11.65 \\
\hline $\mathrm{CO}$ & 0.2 & 0.009 & 1.654 & 10.41 & 0.009 & 1.74 & 9.05 & 17220252.77 & 15722839.49 & 1497413.28 & 11.45 \\
\hline CH4 & 0.2 & 0.008 & 1.654 & 8.73 & 0.008 & 1.74 & 7.59 & 14439592.78 & 13183976.02 & 1255616.76 & 9.60 \\
\hline NH3 & 0.2 & 0.003 & 1.654 & 3.37 & 0.003 & 1.74 & 2.93 & 5571507.79 & 5087028.86 & 484478.94 & 3.71 \\
\hline
\end{tabular}

$T_{b e}=273^{\circ} \mathrm{K}, T_{a f}=261.13^{\circ} \mathrm{K}$, [here subscripts (be) and (af) indicates the before and after the expansion of the gas respectively]

Data (column 1 to 4) collected from (Palchoudhury, 2017a). $F_{d i s c}=F_{b e}-F_{a f}, \mathrm{H}_{\text {disc }}$ is the convert into heat of $F_{\text {disc }}$.

\section{CONCLUSION}

The result of this work show that there is no difference in specific heat of a gas in the isochoric and isobaric process. It is necessary to mention that the inner force in both processes is same due to effect of heat wave force.

\section{REFERENCES}

Palchoudhury, S. (2016). A Modification in Behaviour of Gases. International Journal of Fundamental Physical Sciences (IJFPS), 6(3), 4.

\section{ACKNOWLEDGEMENT}

I, the author, Mr Sankar Palchoudhury express at this moment my sincere gratefulness to the Editor-in-Chief and Editorial staff of the International Journal Fundamental of Physical Science for their valuable suggestion for more efficient representation the article.

Palchoudhury, S. (2017a). About Internal Force of Gases. International Journal of Fundamental Physical Sciences, 7(4), 34-37.

Palchoudhury, S. (2017b). Brownian Motion and Infrared Wave Force. International Journal of Fundamental Physical Sciences(IJFPS), 7(2), 23-24. 